\title{
FORMAÇÃO INICIAL DE PROFESSORES DE MATEMÁTICA DO CURSO DE LICENCIATURA EM PEDAGOGIA: ESTUDOS E REFLEXÕES
}

\author{
LUCIANA MIYUKI SADO UTSUMI
}

\begin{abstract}
RESUMO
O presente texto propõe-se a articular estudos e reflexões acerca da formação inicial dos professores de Matemática do Ensino Fundamental (anos iniciais), no curso de licenciatura em Pedagogia. Tais fundamentos foram sistematizados na pesquisa realizada em torno das necessidades formativas do docente formador, o qual deve articular a discussão acerca do ensino dos conteúdos matemáticos, assim como a respeito das abordagens metodológicas no ensino da Matemática, ao considerar a necessidade da intersecção entre conteúdos matemáticos específicos e questões didático-pedagógicas. A investigação referida fez uma revisão da literatura sobre o histórico do ensino da Matemática e da didática para o Ensino Fundamental, em interface com a formação de professores. A pesquisa de campo previu a coleta de dados por meio da aplicação de questionário e realização de entrevistas, tendo como referência Szymanski (2002, 2004) e Franco (2003) para a análise dos dados. De maneira a contemplar os diferentes olhares e perspectivas que dialogam com a questão da formação de professores de Matemática, em especial, a formação de professores que ensinam Matemática nos anos iniciais do Ensino Fundamental, a discussão dos dados ancorou-se nos referenciais teóricos de autores da Educação e da Educação Matemática. Os resultados indicam que os professores em formação e em atuação licenciados em Matemática igualmente necessitam aprofundar o domínio dos conteúdos matemáticos de ensino; que tanto os alunos dos cursos de graduação em Pedagogia como dos cursos de graduação em Matemática anunciam suas lacunas formativas
\end{abstract}


em termos da necessidade de maior acesso e conhecimento das abordagens metodológicas pautadas nas tendências atuais da didática da Matemática. Nesse sentido, a análise dos dados da pesquisa confirma a necessidade de se considerar a tão proclamada indissociabilidade entre conteúdo e forma na formação de professores de Matemática do curso de graduação em Pedagogia e, em decorrência disso, a necessária busca incessante de formação Matemática continuada por parte do formador de professores desse curso, com base e a partir de suas necessidades formativas próprias, a fim de possibilitar a progressiva e desejada democratização do acesso ao saber matemático por parte dos alunos e alunas dos anos iniciais do Ensino Fundamental.

Palavras-chave: 1. Formação Inicial de Professores. 2. Educação Matemática. 3. Saberes Formativos.

\begin{abstract}
This study highlights the initial training of elementary school mathematics teachers (early years), in the course of degree in Pedagogy and aims at setting the necessary knowledge to university teachers (trainers). The research on the training needs of the trainer teacher must articulate the discussion on the teaching of mathematical content, as well as on the methodological approaches in the teaching of mathematics, considering the need of the intersection of specific mathematical content and didactic and pedagogical issues. In this context, such knowledge must be complementary, in that the teacher takes the decisions regarding what to teach and how to teach. The proposed research conducted a literature review of the history of the teaching of mathematics and didactics for Elementary Education, interfaced with the training of teachers. The field research provided data collection through a questionnaire and interviews, with the reference Szymanski $(2002,2004)$ and Franco (2003) for data analysis. In order to contemplate the different views and perspectives that dialogue with the issue of training of mathematics teachers, in particular, the training of teachers who teach mathematics in the early years of elementary school, the discussion of the data it is anchored in
\end{abstract}


the theoretical authors reference and among other authors. The results indicate that teachers in training and at work graduates in mathematics also need to deepen the field of mathematical education content; both students of undergraduate courses in pedagogy as undergraduate courses in mathematics advertise their training gaps in terms of the need for greater access to and knowledge of methodological approaches guided by the current trends of the teaching of mathematics. In this sense, the analysis of the survey data confirms the need to consider the much-vaunted inseparability of content and form in the formation of undergraduate course of mathematics teachers in pedagogy and, as a result, the necessary relentless pursuit of Mathematics continuing education for the trainer of teachers of this course, on and from their own training needs in order to make possible the progressive and desired democratization of access to mathematical knowledge by pupils and students in the early years of elementary school.

Key-words: 1. Initial Teacher Training. 2. Mathematics Education. 3. Knowledge Formative.

\section{DESENVOLVIMENTO}

Sendo professores, os formadores portam e produzem conhecimentos de e sobre a Matemática, saberes didático-pedagógicos que, nas oportunidades de formação, possi-

bilitam aos formandos, entre outros aspectos, aproximar teoria e prática, romper o isolamento e distanciamento entre disciplinas de conteúdos específicos de Matemática e disciplinas pedagógicas, construir significados no ensinar Matemática.

Vinício de Macedo Santos 


\section{ENTRE OS CAMINHOS TRILHADOS NA INVESTIGAÇÃO, ALGUMAS ROTAS POSSÍVEIS}

Com base na pesquisa anunciada e realizada, ${ }^{1}$ apresenta-se um recorte das análises contempladas no estudo, bem como, das discussões e reflexões teórico-metodológicas decorrentes de cada categoria temática analisada. Para articular os dados coletados aos referenciais teóricos da literatura, buscaram-se as contribuições da pesquisa em Educação e em Educação Matemática, de maneira a contemplar os diferentes olhares e perspectivas que dialogam com a questão da formação de professores de Matemática, em especial, a formação de professores que ensinam Matemática nos anos iniciais do Ensino Fundamental.

\section{CATEGORIA 1 - EDUCAÇÃO MATEMÁTICA NO CURSO DE GRADUAÇÃO EM PEDAGOGIA: LACUNAS E AVANÇOS}

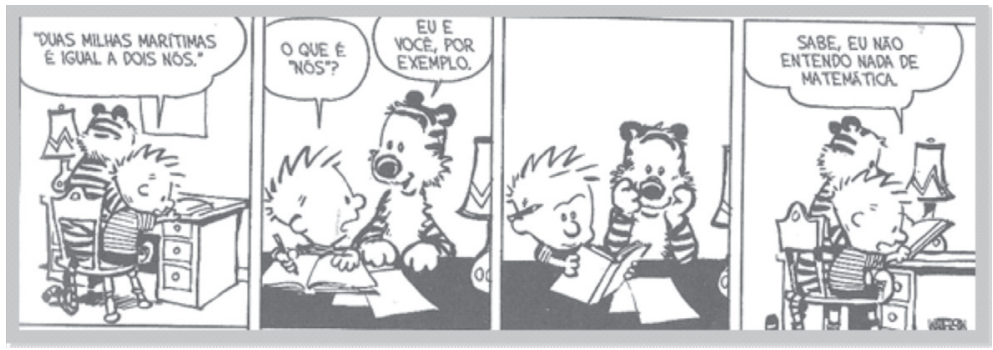

Autoria: Bill Watterson.

Fonte: Watterson (2010).

No que se refere aos conhecimentos e saberes necessários à formação de professores de Matemática para os anos iniciais do Ensino Fundamental, a hipótese inicial levantada era de que os conteúdos relativos às metodologias ou abordagens metodo-

\footnotetext{
1 O presente texto traz um recorte dos fundamentos teóricos e práticos da tese de doutorado defendida em 20 de outubro de 2016. Para saber mais, consulte: UTSUMI, Luciana Miyuki Sado Utsumi. Um estudo sobre os saberes formativos do formador de professores de matemática do curso de licenciatura em Pedagogia, 375p. Tese (Doutorado em Educação) - Escola de Comunicação, Educação e Humanidades da Universidade Metodista de São Paulo, São Bernardo do Campo, 2016. Orientação: Prof ${ }^{a}$. Dr ${ }^{a}$. Norinês Panicacci Bahia.
} 
lógicas do ensino da Matemática (conhecimentos pedagógicos) seriam mais citados em detrimento dos conteúdos matemáticos escolares (conhecimentos específicos). De fato, como na contextualização de Shulman (1992 apud CURI, 2005) ao aludir ao período do "paradigma perdido", constatamos que os sujeitos em formação matemática inicial no curso de graduação em Pedagogia destacam as metodologias de ensino e/ou as abordagens metodológicas como componentes fundamentais para garantia do processo de ensino e de aprendizagem dos conteúdos matemáticos, os quais igualmente são citados, mas em frequência e importância menor para os professores em formação.

Quanto aos conhecimentos que consideram importantes em seus processos formativos, no geral, as professoras de Matemática do Ensino Fundamental $\left(1^{\circ}\right.$. ao $5^{\circ}$. ano) não conseguiram identificar conteúdos específicos trabalhados na graduação em Pedagogia, seja porque não se lembravam, seja porque o curso abordou a Matemática para formação crítica ancorada nos fundamentos teóricos da Educação Matemática e da Educação, o que, para elas, não tem relação direta com a prática em sala de aula e com as necessidades da escola.

Observou-se que as professoras que cursaram também o Magistério atribuíram às metodologias de ensino da Matemática (jogos, Tangran, material dourado, entre outros recursos didáticos) uma importância significativa para uma atuação bem-sucedida na prática docente. Alunos do curso de graduação em Pedagogia destacam os fundamentos/conteúdos matemáticos escolares como significativos para os seus processos formativos, em detrimento de abordagens metodológicas para o ensino da Matemática, o que coloca em evidência a tomada de consciência da importância do domínio dos conteúdos de ensino, imbricados nas metodologias de ensino. Por sua vez, alunos do curso de graduação em Matemática indicam, quase em sua totalidade, a necessidade de aprofundar os conteúdos matemáticos desenvolvidos ao longo de sua formação inicial.

Considerando-se esse panorama, constataram-se que as dificuldades no processo de apropriação dos conteúdos matemáticos de ensino, bem como, o domínio dos respectivos objetos de co- 
nhecimento, não são exclusividade dos professores em formação no curso de graduação em Pedagogia e/ou dos professores em atuação nos anos iniciais do Ensino Fundamental, na medida em que os alunos do curso de graduação em Matemática igualmente apresentam tais lacunas e dificuldades no seu processo de formação inicial e continuada.

Nesse sentido, tanto os professores polivalentes como os professores especialistas manifestaram a necessidade de acesso, retomada, estudo e aprofundamento dos conteúdos matemáticos escolares, uma vez que a formação inicial não contempla todos os conteúdos de ensino da Educação Básica, bem como, não transita por grande parte dos componentes curriculares que serão ensinados pelos futuros professores em seus respectivos níveis de ensino.

Atrelados aos componentes de ensino, os conhecimentos didáticos, com os conhecimentos curriculares, devem constituir os componentes da estrutura universitária na formação de professores de Matemática, em especial no curso de graduação em Pedagogia, tema da presente investigação. Na esteira desta organização curricular, faz-se necessária uma formação inicial mais dinâmica, mais voltada para os desafios do cotidiano escolar quanto ao ensino da Matemática para as crianças, mais focada nos conhecimentos "de" e "sobre" a Matemática, por meio de uma perspectiva integradora dos conhecimentos necessários à formação consistente e crítica do professor de Matemática dos anos iniciais do Ensino Fundamental. Em outras palavras, confirma-se a indissociabilidade entre conteúdo e forma, proclamada e desejada na formação de professores de Matemática, quer nos cursos de graduação em Pedagogia, quer nos cursos de graduação em Matemática.

Sob esse aspecto, coloca-se em pauta a discussão sobre a ampliação da carga horária do curso de graduação em Pedagogia, de modo a possibilitar o aprofundamento dos fundamentos teórico-práticos desenvolvidos no decorrer do processo de formação matemática. Tal ampliação deve ser ancorada em pressupostos diferenciados, no que se refere ao perfil do formador de professores de Matemática do curso de graduação em 
Pedagogia, que igualmente deve se envolver nos processos de formação matemática por meio da pesquisa e da prática reflexiva, a fim de garantir a mediação pedagógica efetiva para a formação de professores de Matemática aptos a se desenvolver em suas futuras atividades docentes em termos qualitativos, associados às pesquisas em Educação e em Educação Matemática.

\section{CATEGORIA 2 - A INTER-RELAÇÃO DO SUJEITO QUE ENSINA COM OS CONTEÚDOS MATEMÁTICOS}

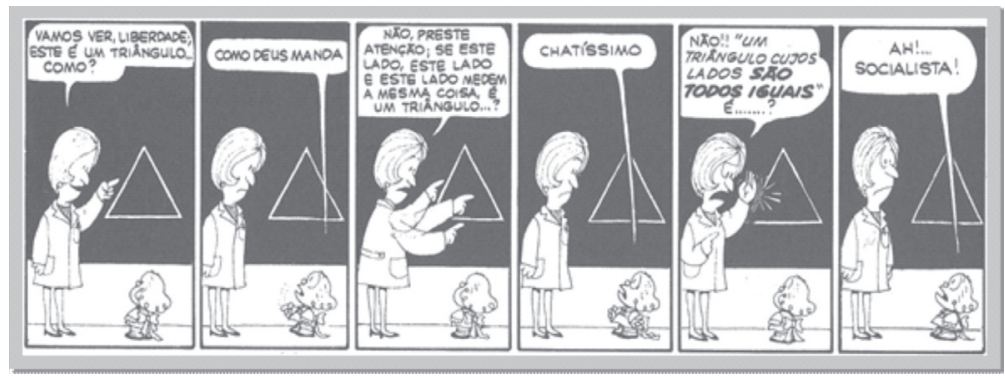

Autoria: J.L. Quino.

Fonte: Quino (2010).

Estudos constatam a íntima relação entre a formação e a atuação docente, bem como, entre a relação que os professores estabelecem com os conteúdos matemáticos de ensino e as suas práticas pedagógicas, acarretando condições favoráveis ou desfavoráveis para o processo de ensino e de aprendizagem da Matemática escolar.

Os alunos do curso de graduação em Pedagogia carregam as crenças e as experiências negativas em relação à Matemática escolar, construídas ao longo da escolaridade básica, em especial da Matemática que tiveram que aprender nos anos finais do Ensino Fundamental, bem como, no Ensino Médio. Suas experiências de fracasso nas aprendizagens da Matemática acabam por configurar representações e crenças em relação aos conteúdos matemáticos que precisarão ensinar futuramente aos seus alunos.

Torna-se necessário, portanto, vislumbrar uma proposta de formação inicial que dê condições para que o futuro professor possa redimensionar, de maneira positiva, sua relação com os 
conteúdos matemáticos, por meio de uma formação em conhecimentos específicos e pedagógicos, em especial, em conteúdos matemáticos de ensino dos primeiros anos de escolaridade. Há que se superar a concepção segundo a qual os professores polivalentes não necessitam de conhecimentos específicos, cabendo, assim, reproduzir os "conteúdos elementares" aos quais tiveram acesso na condição de aprendiz na Educação Básica, assim como, superar a situação na qual são vistos como portadores de conhecimentos matemáticos rasos e superficiais (PONTE, 1992).

Para tanto, coloca-se em evidência a formação do formador de professores no curso de graduação em Pedagogia, no que se refere, de maneira análoga, ao domínio dos conteúdos de ensino e dos saberes pedagógicos. Suas práticas formativas devem ser ancoradas em propostas que articulem as múltiplas dimensões da formação do professor de Matemática, com uma atenção especial aos conteúdos específicos, visto que as pesquisas têm constatado um cenário desolador e preocupante em relação a esse quesito.

É importante destacar que os alunos do curso de graduação em Matemática identificam dificuldades no processo de aquisição dos conteúdos matemáticos mais elaborados, referentes à proposta curricular em nível de Ensino Superior. Apresentam preocupações referentes ao domínio desses conteúdos específicos, bem como, à aquisição dos conteúdos de ensino, em detrimento dos conteúdos pedagógicos.

Estudos denunciam lacunas na formação inicial dos cursos de graduação em Matemática, no que se refere a uma ênfase nos conteúdos específicos, muitos dos quais não dialogam com o campo da Matemática escolar, impondo aos futuros professores, bem como aos seus formadores, a busca contínua por apropriação dos conteúdos de ensino dos anos finais do Ensino Fundamental e do Ensino Médio, desmistificando a ideia de que o professor especialista tem domínio dos conteúdos matemáticos de ensino, e que "basta ter domínio dos conteúdos para saber ensinar".

Assim como no curso de graduação em Pedagogia, há a necessidade de revisitar os conteúdos matemáticos de ensino e ressignificá-los por meio da articulação com os conhecimentos didáticos e pedagógicos. Tais saberes docentes são fundamentais 
no repertório do formador de professores no curso de graduação em Matemática.

As professoras polivalentes de Matemática relataram que gostam de ensinar Matemática e que a relação com os conteúdos se dá de forma tranquila, uma vez que estão sempre estudando para ensinar com segurança, por meio da apropriação de metodologias pautadas nas tendências atuais para o ensino da Matemática, bem como, pelo desenvolvimento de saberes profissionais que balizam suas práticas pedagógicas. Por sua vez, as professoras especialistas expressam uma grande preocupação quanto ao domínio dos conteúdos de ensino, demandando das mesmas um estudo sistemático e contínuo dos conhecimentos matemáticos, bem como, a busca contínua de estratégias metodológicas que garantam o processo de ensino e de aprendizagem.

\section{CATEGORIA 3 - CRENÇAS ACERCA DO PROCESSO DE ENSINO E APRENDIZAGEM DA MATEMÁTICA: REPRODUÇÃO OU SUPERAÇÃO DOS/NOS PROCESSOS FORMATIVOS}

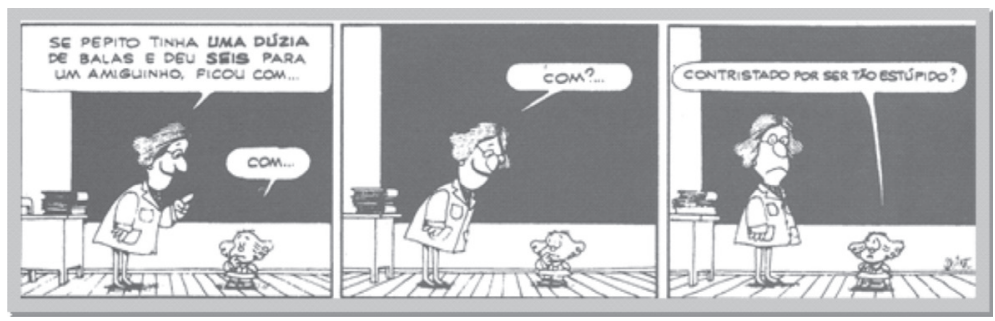

Autoria: J.L. Quino.

Fonte: Quino (2010).

As análises indicam a superação inicial e parcial das crenças em relação ao ensino e a aprendizagem da Matemática por parte dos alunos do curso de graduação em Pedagogia, resgatando a disponibilidade para a busca de aprofundamento dos conteúdos matemáticos dos anos iniciais do Ensino Fundamental. Contudo, constata-se, ainda, a insegurança em ensinar conteúdos matemáticos que não foram por eles apropriados na educação básica, evidenciando a necessidade de uma formação pedagógica 
consistente que conduza à reconstrução da experiência por parte do professor-aprendiz.

Nesse sentido, o formador dos professores de Matemática do curso de graduação em Pedagogia deve vislumbrar práticas formativas que considerem os conhecimentos específicos, os conhecimentos pedagógicos e os conhecimentos curriculares dos anos iniciais do Ensino Fundamental, de modo que os futuros professores de Matemática possam superar as crenças e os rótulos associados ao "bicho de sete cabeças" do currículo escolar.

É fundamental, portanto, que o professor de Matemática exercite a reflexão sobre suas práticas de ensino, de modo que possa ter clareza de suas concepções a respeito da Matemática e as variáveis envolvidas no processo de ensino e aprendizagem da mesma: o aluno, o professor e o saber matemático. Assim, o professor deverá:

a) Em relação ao saber matemático: identificar as principais características dessa ciência, sua natureza, seus conteúdos, suas ramificações e aplicações práticas, de modo que possa fazer a "ponte" - transposição didática - entre a Matemática como Ciência e a Matemática escolar.

b) Em relação aos alunos: conhecer os alunos em suas características e condições subjetivas, sociológicas, psicológicas, culturais, enfim, numa perspectiva de sujeito integral e complexo; de modo a considerar seus conhecimentos prévios na construção de conhecimentos e aprendizagens fundamentais.

c) Em relação à sua formação profissional: saber que suas concepções acerca da Matemática influenciam diretamente suas práticas de ensino, a seleção de conteúdos matemáticos, a definição de objetivos de ensino, a escolha de materiais e recursos pedagógicos e a forma de avaliação.

A partir deste breve panorama, podemos constatar, com base em Oliveira (2012, p. 70), que é fundamental pensarmos 
que "uma alternativa mais promissora daqui para a frente poderia ser a investigação de crenças e concepções sobre conteúdos matemáticos específicos ensinados nos anos iniciais, de maneira a fornecer mais subsídios para a elaboração de propostas de formação para os cursos formadores de professores dos anos iniciais", a fim de conhecer e superar tais crenças acerca da aprendizagem da Matemática, de modo que possamos garantir a efetiva aprendizagem dos conteúdos matemáticos de forma prazerosa e bem-sucedida, promovendo a verdadeira democratização do acesso a esse conhecimento.

\section{CATEGORIA 4 - NECESSIDADES FORMATIVAS NO PROCESSO DE ENSINO E APRENDIZAGEM DA MATEMÁTICA E FORMAÇÃO DE PROFESSORES}

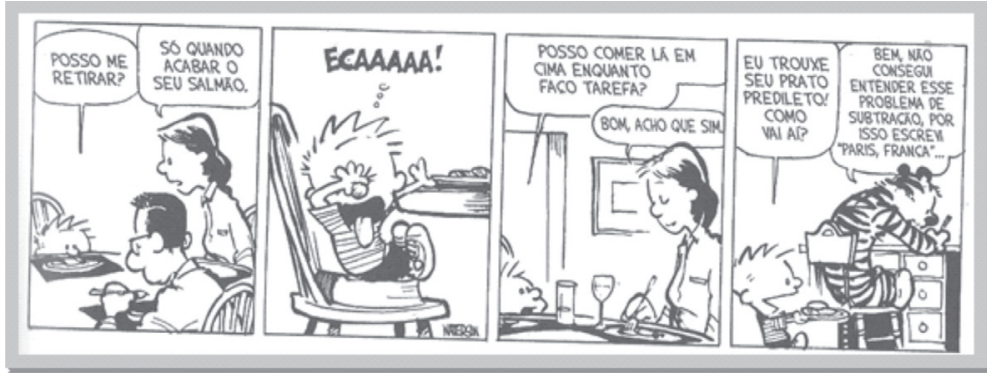

Autoria: Bill Watterson.

Fonte: Watterson (2010)

Como muitas professoras não procuram por temas relacionados à Matemática em sua formação continuada, não puderam pontuar as necessidades formativas. Porém, aquelas que buscam formação continuada na Matemática pontuaram a necessidade de se apropriarem das tendências atuais no ensino da Matemática na dimensão do "saber fazer", convergindo com as expectativas de superação das lacunas no processo formativo por parte dos alunos do curso de graduação em Pedagogia que, em sua maioria, sugere a inserção de aulas mais práticas no desenvolvimento das disciplinas relacionadas à Matemática na formação inicial de professores. 
As professoras e os alunos dos cursos de graduação em Pedagogia pontuaram a necessidade de busca de aperfeiçoamento constante para aprimorar a prática docente e garantir a aprendizagem da Matemática por parte de seus futuros alunos dos anos iniciais do Ensino Fundamental, possivelmente em decorrência de suas preocupações didático-pedagógicas no sentido de conferir significado aos conteúdos matemáticos.

Algumas professoras pontuaram a consideração dos aspectos qualitativos em detrimento dos aspectos quantitativos no processo de ensino e aprendizagem da Matemática, por exemplo, dar mais tempo de aula para atividades processuais nas quais os alunos constroem conhecimento matemático, ao invés de dar ênfase em exercícios de fixação e memorização mecânica.

Os professores em formação no curso de graduação em Pedagogia conseguem refletir sobre a importância de garantir um aprendizado com significado dos conteúdos matemáticos, ao fazerem a crítica às práticas de ensino tradicionais e buscarem por metodologias que dialoguem com as tendências atuais do ensino da Matemática.

Entre as necessidades formativas apontadas, podemos identificar as que se referem à falta de domínio do conteúdo matemático por parte das professoras em formação do curso de graduação em Pedagogia. Em outra perspectiva, encontramos indicadores de fragilidades quanto ao domínio de metodologias de ensino da Matemática, por parte das professoras em atuação nos anos iniciais do Ensino Fundamental.

Frente à proclamada necessidade de integração dessas duas dimensões na formação dos professores polivalentes que ensinam Matemática, os formadores desses professores, quer em cursos de graduação em Pedagogia, quer em cursos de graduação em Matemática, preconizam ações formativas que levam em consideração a indissociabilidade entre esses saberes na formação dos professores, bem como, valorizam a prática de pesquisa como meio de articular tais dimensões na formação inicial e na formação continuada de professores de Matemática dos anos iniciais do Ensino Fundamental. 
As lacunas ainda presentes nos processos formativos dos diferentes atores sociais que ensinam Matemática devem considerar que a qualificação e a profissionalização do professor de Matemática concretizam-se por meio da interação entre os saberes acadêmicos adquiridos na formação inicial e entre os saberes da experiência profissional construídos nos espaços onde atuam na formação continuada em serviço, imprimindo qualidade nos processos de ensino e de aprendizagem da Matemática.

\section{CATEGORIA 5 - REPRESENTAÇÕES/ASPECTOS QUE FAVORECEM O APRENDIZADO DA MATEMÁTICA ESCOLAR}
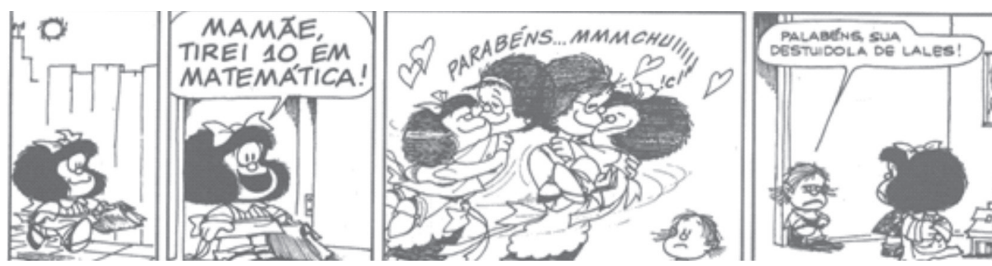

Autoria: J.L. Quino.

Fonte: Quino (2010).

Os relatos das práticas pedagógicas bem-sucedidas transitam por aspectos teóricos e práticos no ensino de Matemática, como o uso de jogos, atividades práticas/vivenciais para o desenvolvimento dos conteúdos matemáticos nos diferentes segmentos de ensino do $1^{\circ}$. ao $5^{\circ}$. anos do Ensino Fundamental. O movimento de seleção de tais práticas de ensino da Matemática, consideradas pelas professoras como sendo bem-sucedidas, possivelmente deflagrou em cada uma delas a reflexão crítica, agora "sobre" as suas ações, de modo a identificar os fatores, os aspectos, as características e os critérios que definiram tais práticas.

Podemos constatar a utilização de diversos materiais concretos, recursos didáticos, jogos, espaços diferentes da sala de aula convencional, técnicas dinâmicas e centradas no aluno, atividades de simulação de venda e compra, entre outras possibilidades de ensinar e de aprender Matemática nos anos iniciais do Ensino Fundamental. Aos formadores dos cursos de graduação em Peda- 
gogia, cabe desenvolver tais abordagens metodológicas pautadas nas tendências atuais do ensino da Matemática, a fim de possibilitar aos futuros professores as experiências didático-pedagógicas que farão parte de seu repertório profissional docente.

Observaram-se nas práticas formativas dos docentes formadores de professores de Matemática aspectos que garantem uma formação consistente, articulada e integrada dos futuros professores de Matemática, em consonância com os desafios atuais do ensino da matemática escolar nos seus respectivos espaços de atuação docente.

\section{CONSIDERAÇÕES FINAIS}

Que possamos vislumbrar uma formação de professores capaz de concretizar a "passagem do estabelecido para o inventado" (RIOS, 2001), em prol de uma Educação Matemática que dialogue com a realidade de nossos aprendizes.

Com o intuito de tornar público e compartilhar os conhecimentos, os saberes, as contribuições da pesquisa sobre a formação de professores decorrentes de estudos consolidados e da pesquisa realizada, apresentamos um quadro que reúne as ideias essenciais acerca das necessidades formativas do formador de professores de Matemática dos anos iniciais do Ensino Fundamental.

As necessidades formativas apresentadas no quadro são decorrentes de investigações realizadas por pesquisadores da área da Educação e da Educação Matemática (ARAGÃO, 2012; CURI, 2005; MARCONCIN, 2009; MARTINS, 2014; MEGID, 2013; NACARATO, MENGALI, PASSOS, 2014b; OLIVEIRA, 2007, 2012; ORTEGA, SANTOS, 2008; SANTOS, ORTEGA, FANIZZI, 2014), as quais foram rigorosamente selecionadas, a fim de se constituírem num repertório de saberes docentes e saberes profissionais necessários à construção da identidade docente profissional do formador de professores de Matemática dos anos iniciais do Ensino Fundamental, em sua atuação no curso de graduação em Pedagogia. 
Segundo Curi (2005, p. 161), as categorias de análise - o conhecimento do conteúdo da disciplina, o conhecimento didático do conteúdo da disciplina e o conhecimento do currículo - "[...] embora apareçam imbricadas na ação do professor, desmembradas, são uma ferramenta muito útil no processo de seleção e organização de conteúdos a ensinar, tanto os conceituais como os procedimentais e atitudinais". Considerando a homologia de processos, as categorias desmembradas no quadro, a seguir, podem constituir-se, para os formadores do curso de graduação em Pedagogia, em ferramenta pedagógica para o planejamento, a organização e a efetivação de práticas diferenciadas de formação de professores de Matemática dos anos iniciais do Ensino Fundamental.

Quadro - Necessidades formativas do formador de professores de Matemática dos anos iniciais do Ensino Fundamental no curso de graduação em Pedagogia.

\section{CONHECIMENTOS ESPECIFICOS}

Tratamento dos conteúdos matemáticos de modo que considerem as diferenças de faixa etária, seus ritmos cognitivos e formas próprias de aquisição dos conteúdos.

Atribuição de sentidos e significados aos conhecimentos e processos matemáticos.

Domínio dos conhecimentos matemáticos dos níveis de ensino nos quais o futuro professor vai atuar, em especial, dos anos iniciais do Ensino Fundamental, além de ter um conhecimento aprofundado sobre os mesmos e os seus processos de aplicação e articulação com outros campos de conhecimento.

Garantia aos futuros professores de uma base sólida dos conteúdos elementares da Matemática dos anos iniciais do Ensino Fundamental, de modo a fornecer a base de sustentação para outros conhecimentos mais avançados a serem construídos posteriormente na Matemática.

Organização de práticas formativas que promovam o encontro entre alunos de graduação em Pedagogia e alunos de graduação em Matemática, a fim de superar as lacunas de conhecimentos matemáticos e de conhecimentos pedagógicos por meio da troca de saberes e de experiências. 
Explicitação de como os conteúdos matemáticos se relacionam com outras partes do currículo escolar.

Desenvolvimento de práticas formativas para aprimorar capacidades como resolver problemas, argumentar, estimar, raciocinar matematicamente, comunicar-se matematicamente. Desenvolver atitudes positivas nos futuros professores é essencial em relação à Matemática e seu ensino, ter predisposição para usar conhecimentos matemáticos como recursos para interpretar, analisar e resolver problemas, ter perseverança na busca de resultados, interesse em utilizar diversas representações matemáticas e confiança em si mesmos para aprender e ensinar Matemática.

Busca de ações integradoras que respondam às demandas dos professores em formação, que podem ensejar nova parceria docente ou consulta a profissionais de outras áreas, a fim de contribuir no processo de ensino e aprendizagem, uma vez que, ao lidar com a integração de conhecimentos específicos em formação, o futuro professor desenvolve a atitude interdisciplinar de busca por conhecimentos em outras áreas para a compreensão de certo fenômeno em estudo. Essa atitude passa a fazer parte de seu repertório docente.

Condições ao professor em formação para tomar consciência da estreita relação entre os conhecimentos específicos e as possibilidades de práticas diferenciadas de Ensino, pois, na medida em que os estudantes se apropriam do conteúdo curricular específico em estudo, (re)elaboram e redimensionam o ato de ensinar em termos de espaço, tempo, conteúdo e forma (diferente daquela que estudaram quando crianças).

Adoção de uma epistemologia de formação inicial de professores que concebe o licenciando como sujeito de sua própria formação, em que a prática formativa propicie a ele experienciar como aluno, modelos e recursos didáticos, atitudes e maneiras de organização docente pretendidos na sua futura prática pedagógica, objetivando o alargamento de suas capacidades de reflexão e de autonomização. Assim, é possível que ele situe no contexto do Ensino - por meio da Simetria Invertida - suas experiências escolares e a vivência no curso de formação docente com o olhar do presente carregado de questões teórico-práticas e vislumbre a mobilização desses conhecimentos na futura docência. Portanto, em processos de formação que visem à perspectiva metodológica da Simetria Invertida há que propiciar a reflexão sobre experiência do sujeito naquele contexto formativo e manifestação - individual ou coletiva; oral ou escrita - das ideias produzidas, tendo em vista a futura prática docente. 
Promoção de processos formativos que levem a contestar o Ensino tradicional livresco, verbalístico e de memorização, buscando um "novo" modelo que não é dado pronto, formatado, onde cada qual (formador e licenciando) precisa ser partícipe da construção desse outro modelo, porque implica constituir-se também professor. Tal proposição ressalta o papel do metaensino em condição sine qua non no processo de formação inicial docente. A ação educativa de fazer circular certos discursos teórico-práticos, metodológicos e epistemológicos sobre o Ensino se inicia de maneira intencional pelo formador. É ele quem orienta e medeia os processos comunicativos em aula, colocando em jogo questões e argumentos referentes aos componentes de formação básica e específica do futuro professor dos anos iniciais.

Adoção da abordagem pedagógica por meio de pesquisa em aula, a fim de propiciar aos licenciandos a vivência de práticas interdisciplinares, de modo que eles próprios buscassem caminhos em outras áreas e refletissem sobre tais possibilidades docentes para suas futuras práticas profissionais.

Exercício de comparações entre os pontos de vista dos estudantes em desacordo, promover explicações que se façam necessárias, confrontar tarefas realizadas. Isto é, favorecer a interação entre os aprendizes, ou seja, assumir o papel de professor mediador em processos de aprendizagem. Promover essa mediação associada à aprendizagem cooperativa, entre futuros professores, poderá ser um indicador de simetria invertida, ou seja, será uma experiência vivida por esses estudantes, a partir da qual se espera que, como futuros professores a desenvolvam em suas práticas profissionais.

Integração entre os princípios didático-metodológicos e os formativos, constituindo-se em princípios integradores na formação de professores de Matemática.

Acesso às pesquisas da Educação Matemática que contribuam para que essa formação possa vir a contemplar as dimensões históricas e sociais da Matemática e da Educação Matemática, numa perspectiva problematizadora das ideias matemáticas e educacionais, promovendo mudanças de crenças, valores e atitudes prévios, visando a uma Educação Matemática crítica, e que possa propiciar a experimentação e a modelagem de situações semelhantes àquelas que os futuros professores terão que gerir.

\section{CONHECIMENTOS PEDAGOGICOS}

Possibilidade do diálogo entre professores de Matemática e professores de outras disciplinas; entre professores que atuam no mesmo nível de ensino e professores que atuam em níveis de ensino diferentes; entre comunidades de especialistas de diversas áreas de ensino e de pesquisa. 
Utilização de casos de ensino como ferramentas pedagógicas potencializadoras da reflexão sobre a prática e da produção de saberes docentes a partir da prática, uma vez que estão ligados à ação e se referem aos saberes contextualizados.

Criação e proposta de um ambiente positivo que encoraje os alunos a propor soluções, explorar possibilidades, levantar hipóteses, justificar seu raciocínio e validar suas próprias conclusões. Respostas "incorretas" constituem a riqueza do processo de aprendizagem e devem ser exploradas e utilizadas de maneira a gerar novo conhecimento, novas questões, novas investigações ou refinamento das ideias existentes.

Consideração de forma enfática das ocorrências da sala de aula dos anos iniciais, do repertório real que lá é encontrado, trazendo os episódios vivenciados nos estágios realizados pelos alunos para discussão durante as aulas.

Envolvimento dos futuros professores com a observação, descrição e discussão de aulas de Matemática de professores dos anos iniciais, em confronto com leituras realizadas, pode constituir uma ferramenta poderosa para a construção de uma futura prática reflexiva e crítica, ao mesmo tempo em que aproxima os futuros professores de questões didático-metodológicas e de conteúdos matemáticos, desde que bem exploradas e sistematizadas pelo formador, possibilitando a articulação entre teoria e prática.

Formação do futuro professor para dar importância ao ensino da Matemática pautado na compreensão e na construção de conhecimentos pelos alunos. Um ensino da Matemática que se preocupa mais com o desenvolvimento de ferramentas e de estratégias de resolução de problemas do que com a reprodução de modos de operar; que prima pela aplicação dos conhecimentos escolares em situações diversas; que instrumentaliza o aluno no desenvolvimento de sistemas de representação; que extrapola os muros da escola, contribuindo para o desenvolvimento de um modo de ver e de pensar matematicamente as situações escolares e extraescolares.

Promoção da investigação de um problema de caráter profissional, levando em conta o contexto de atuação dos futuros professores, de forma a possibilitar um processo de indagação, reflexão e estudo por parte deles, no sentido de realmente se sentirem implicados e interessados.

Garantia da indissociabilidade entre conteúdo-forma, por meio de práticas formativas que articulem conhecimentos matemáticos, didáticos, curriculares, teóricos e práticos.

Domínio da comunicação, da organização da aprendizagem, que devem referir-se às formas que o professor vai empregar para tornar os conteúdos possíveis de serem aprendidos pelos alunos, ou seja, o "como ensinar". 
Garantia do aprofundamento dos conhecimentos sobre o planejamento do ensino, acerca das rotinas e recursos instrucionais, a respeito das características das interações entre os conteúdos matemáticos e sobre as tarefas a serem realizadas.

Estímulo dos professores em formação a frequentar as escolas de estágio para acompanhar professores mais experientes.

Valorização da atividade de pesquisa como conhecimento, ou seja, a pesquisa sendo o eixo da formação docente, traduzida na organização curricular, onde as disciplinas sejam planejadas com o objetivo de desenvolver habilidades e atitudes de investigação.

Discussões sobre estilos de aprendizagem dos alunos, seus interesses, suas necessidades e eventuais dificuldades e a gestão de sala de aula, entre outros temas relacionados ao processo de ensino e de aprendizagem da Matemática.

Oportunidades para que os professores em formação possam analisar processos de aprendizagem dos alunos, suas dificuldades, propor e analisar situações didáticas, avaliar o desempenho dos alunos e a própria prática docente no ensino da Matemática.

Reflexão sobre os possíveis erros dos alunos e acerca dos equívocos conceituais dos próprios futuros professores, como estratégia metodológica para resgatar a confiança na capacidade de aprender Matemática e, assim, promover o repensar a respeito de ensinar e aprender Matemática.

Incentivo aos professores em formação matemática a participarem de grupos colaborativos, a fim de desenvolver uma atitude investigativa e a percepção da importância do trabalho coletivo, que serão aprendizagens fundamentais no decorrer de sua atividade docente.

Estímulo ao engajamento do futuro professor em comunidades de aprendizagem, nas quais ele tenha a oportunidade de compartilhar ideias, sentimentos, conhecimentos, experiências e dúvidas com seus colegas de curso, com professores da universidade (licenciados em Pedagogia e em Matemática) e das escolas e pesquisadores relacionados à área da Matemática (Educação e Educação Matemática).

Planejamento de situações didáticas pautadas na perspectiva construtivista, estabelecendo a interação entre os componentes do processo de ensino e de aprendizagem da Matemática: o professor, o aluno e o conhecimento matemático.

Promoção da dimensão formadora da prática com atividades concretas de formação que levem os futuros professores a assumirem uma postura crítica e reflexiva diante das práticas de ensino da Matemática, seja nos espaços da instituição formadora, seja nos espaços dos estágios supervisionados. 
Discussão com os futuros professores a respeito dos aspectos de práticas frequentes no ensino da Matemática que acarretam dificuldades nas aprendizagens de noções básicas de Matemática (noção de número, algoritmos das operações básicas, frações, entre outras), problematizando as abordagens dessas noções.

Utilização de recursos didáticos específicos para o ensino de Matemática sem negligenciar os conteúdos matemáticos.

Promoção de práticas formativas entre formadores de professores de $\mathrm{Ma}$ temática do curso de graduação em Pedagogia e formadores de professores de Matemática do curso de graduação em Matemática.

\section{CONHECIMENTOS CURRICULARES}

Condições para que as futuras professoras produzam narrativas autobiográficas, possibilitando uma importante prática de formação; pois essas narrativas não apenas revelam as crenças dessas alunas/professoras com relação ao ensino e à aprendizagem de Matemática, como também possibilitam identificar tendências didático-pedagógicas de determinada época, como também trazem marcas de um período histórico da Educação Matemática.

Conhecimento das questões relacionadas ao trabalho do professor de $\mathrm{Ma}$ temática dos anos iniciais, de modo a poder promover o desenvolvimento da competência profissional dos futuros professores.

Apresentação aos professores em formação dos resultados de pesquisa sobre desenvolvimento profissional do professor de Matemática, no contexto da Educação Matemática - considerando-a uma subárea da Educação - é fundamental.

Formação de professores autônomos, que refletem sua prática, que tomam decisões e não apenas ministram aulas de conteúdos específicos de Matemática.

Estabelecimento de projetos formativos em parceria com os professores da escola, a fim de possibilitar um contexto favorável para a construção/ reconstrução de conceitos matemáticos.

Atenção à organização da Prática de Ensino e do Estágio Supervisionado como possíveis espaços de formação reflexiva.

Resgate das aprendizagens dos professores em formação e sua reflexão sobre sua prática docente, sempre buscando o aprimoramento do processo de ensinar e de aprender.

Explicitação, por parte dos professores em formação, de seus conhecimentos prévios, de suas dificuldades, de suas ideias sobre os conhecimentos matemáticos e seu ensino, colocando essas ideias em xeque, a fim de superar as crenças que sustentam acerca do ensino e da aprendizagem de Matemática. 
Formação do futuro professor para ter compreensão da Matemática que traduza em um conhecimento explícito. Deve ser capaz de conversar sobre Matemática e não apenas de descrever procedimentos, ser capaz de explicar o porquê, de relacionar ideias particulares ou procedimentos matemáticos e também de relacionar a Matemática com outras áreas do conhecimento.

Formação do futuro professor para conhecer bem os conceitos e processos matemáticos do nível de escolaridade em que vai atuar.

Condições para que os futuros professores tenham uma noção clara de todo o currículo de Matemática, do ciclo em que atuarão e das ideias matemáticas fundamentais que podem ser trabalhadas com seus alunos.

Compreensão do programa curricular, dos materiais que o professor disponibiliza para ensinar Matemática, da capacidade de fazer articulações horizontais e verticais do conteúdo a ser ensinado, da história da evolução curricular do conteúdo a ser ensinado.

Consideração das pesquisas na área da Educação Matemática, em particular sobre o ensino e a aprendizagem de Matemática nos anos iniciais, como balizadores de seu trabalho formativo junto aos futuros professores de Matemática.

Leitura e reflexão sobre os projetos curriculares - o geral (oficial) e o local (de uma escola) - de modo a problematizá-los e levar o futuro professor de Matemática a ajustar tais propostas curriculares à sua realidade de atuação profissional e, assim, dando condições para que o currículo praticado em sala de aula garanta efetivamente o ensino da Matemática.

Compartilhamento do "projeto curricular" próprio com os pares, de modo que o repertório de ideias, conceitos, concepções e orientações, construídos ao longo da nossa formação escolar e profissional, possam contribuir para a reflexão coletiva e para o fortalecimento das práticas curriculares para o ensino da Matemática.

Exercício de um olhar atento aos formuladores de currículos, aos gestores de políticas públicas, aos gestores de escolas, aos educadores matemáticos, aos elaboradores de materiais didáticos, aos pesquisadores em Educação e em Educação Matemática, entre outros agentes que viabilizam propostas para o ensino de Matemática nos anos iniciais do Ensino Fundamental.

Seleção dos materiais curriculares que garantem a efetiva realização de um ensino de Matemática articulado e acessível a todos os alunos.

Análise dos documentos curriculares, os recursos didáticos, os livros didáticos, as pesquisas científicas e outros materiais voltados ao ensino da Matemática.

Consideração do ensino e da aprendizagem da Matemática como direitos constitucionais.

Fonte: A autora. 
Sem dúvida, os desafios postos à formação dos professores e das professoras que atuam nos anos iniciais são grandes. No que diz respeito à formação inicial, o desafio consiste em criar contextos em que as crenças que essas futuras professoras foram construindo ao longo da escolarização possam ser problematizadas e colocadas em reflexão, mas, ao mesmo tempo, que lhes possibilitem tomar contato com os fundamentos da Matemática de forma integrada às questões pedagógicas, pautadas nas atuais tendências em Educação Matemática. Sem investimentos na formação inicial, dificilmente conseguiremos mudar a situação da escola básica, em especial, da forma como a Matemática ainda é ensinada (NACARATO; MENGALI; PASSOS, 2014).

Assim, trata-se justamente de pensar o que nos compete, como profissionais da Educação, em busca permanente de sentidos para uma ação pedagógica compreensiva que contemple, por sua vez, os desafios da profissão docente neste século XXI e da formação de professores de Matemática, em prol do "exercício de uma docência responsável, ética e comprometida com um projeto de sociedade mais humana" (MELO, 2005, p. 1).

\section{REFERÊNCIAS}

ARAGÃO, Rosália Maria Ribeiro de. Surpresas etnomatemáticas: a gente pode saber matemática sem ter aprendido na escola?! In: MENDES, Iran Abreu; LUCENA, Isabel Cristina Rodrigues (Orgs.). Educação Matemática e cultura Amazônica: fragmentos possíveis. Belém (PA): Açaí, 2012.

CURI, Edda. A matemática e os professores dos anos iniciais. São Paulo: Musa, 2005.

FRANCO, Maria Laura P. B. Análise de conteúdo. Brasília (DF): Plano, 2003. MARCONCIN, Isabel Cristina. Princípios subjacentes às práticas pedagógicas em matemática de professoras nas séries iniciais do ensino fundamental, 2009. Dissertação (Mestrado em Educação) - Setor de Educação, Universidade Federal do Paraná, Curitiba (PR), 2009.

MARTINS, France Fraiha. Significação do ensino de ciências e matemática em processos de letramento científico-digital, 2014. Tese (Doutorado) Universidade Federal do Pará. Instituto de Educação Matemática e Científica. Programa de Pós-graduação em Educação em Ciências e Matemáticas. Belém (PA), 2014.

MEGID, Maria Auxiliadora Bueno Andrade. A teoria na prática é outra? Constituindo-se professoras de matemática dos primeiros anos do ensino fundamental. Horizontes, v. 31, n. 1, p. 31-40, jan./jun. 2013. 
MELO, Geovana Ferreira. Em questão: o lugar dos saberes docentes. Cadernos da FUCAMP, v. 4, n. 4. Monte Carmelo (MG): FUCAMP, 2005.

NACARATO, Adair Mendes; MENGALI, Brenda Leme da Silva; PASSOS, Carmen Lúcia Brancaglion. A formação matemática das professoras polivalentes: algumas perspectivas para práticas e investigações. In: NACARATO, Adair Mendes; MENGALI, Brenda Leme da Silva; PASSOS, Carmen Lúcia Brancaglion. A matemática nos anos iniciais do ensino fundamental: tecendo fios do ensinar e do aprender. Belo Horizonte (MG): Autêntica, 2014b. (Tendências em Educação Matemática).

OLIVEIRA, Ana Teresa de Carvalho Correa de. Saberes e práticas de formadores de professores que vão ensinar matemática nos anos iniciais, 2007. Tese (Doutorado em Educação) - Pontifícia Universidade Católica (PUC), Rio de Janeiro, 2007.

OLIVEIRA, Gaya Marinho de. A matemática na formação inicial de professores dos anos iniciais: uma análise de teses e dissertações defendidas entre 2005 e 2010 no Brasil, 2012, 240 p. Dissertação (Mestrado em Ensino de Matemática) - Universidade Federal do Rio de Janeiro, Instituto de Matemática. Rio de Janeiro, 2012. Disponível em: <http://www.pg.im.ufrj.br/pemat/48\%20 Gaya\%20Oliveira.pdf>. Acesso em: 12 mar. 2013.

ORTEGA, Eliane Maria Vani; SANTOS, Vinicio de Macedo. Formação de professores no contexto da educação matemática. Série Estudos (Periódico do Mestrado em Educação da UCDB). Campo Grande (MS), n. 26, p. 11-22, jul./dez. 2008.

PONTE, João Pedro da. Concepções de professores de matemática e processos de formação. In: PONTE (Org.). Educação Matemática: temas de investigação. Lisboa: Instituto de Inovação Educacional, 1992, p. 185-239.

RIOS, Terezinha Azeredo. Ética e competência, 11, ed. v. 16. São Paulo: Cortez, 2001. (Coleção Questões da Nossa Época).

SANTOS, Vinício de Macedo. "Sobre avaliações e avaliação em matemática: a Finlândia não é aqui!”. In: SANTOS, Vinício de Macedo; ORTEGA, Eliane Maria Vani; FANIZZI, Sueli (col.). Ensino de matemática na escola de nove anos: dúvidas, dívidas e desafios. São Paulo: Cengage Learning, 2014d, p. 57-71. (Ideias em Ação).

SZYMANSKI, Heloísa (Org.). A entrevista na pesquisa em educação - a prática reflexiva, 3. ed. Brasília (DF): Liber, 2004.

SZYMANSKI, Heloisa; ALMEIDA, Laurinda Ramalho de; PRANDINI, Regina Célia Almeida Rego. Entrevista reflexiva: um olhar psicológico sobre a entrevista em pesquisa. In: SZYMANSKI, Heloisa (Org.); ALMEIDA, Laurinda Ramalho de; PRANDINI, Regina Célia Almeida Rego. A entrevista na pesquisa em educação: a prática reflexiva. Brasília (DF): Plano, 2002, p. 9-61. SZYMANSKI, Heloisa; ALMEIDA, Laurinda Ramalho de; PRANDINI, Regina Célia Almeida Rego. Perspectivas para a análise de entrevistas. In: SZYMANSKI, Heloisa (Org.); ALMEIDA, Laurinda Ramalho de; PRANDI- 
NI, Regina Célia Almeida Rego. A entrevista na pesquisa em educação: a prática reflexiva. Brasília: Plano Editora, 2002b, p. 63-86.

UTSUMI, Luciana Miyuki Sado Utsumi. Um estudo sobre os saberes formativos do formador de professores de matemática do curso de licenciatura em Pedagogia, 375p. Tese (Doutorado em Educação) - Escola de Comunicação, Educação e Humanidades da Universidade Metodista de São Paulo, São Bernardo do Campo, 2016. Orientação: Prof ${ }^{a}$. Dr ${ }^{a}$. Norinês Panicacci Bahia. 